\title{
Desmitificando la violencia escolar: un análisis crítico de las representaciones
}

\author{
Nicolás Patierno, Ph.D. \\ Universidad Nacional de La Plata, Argentina* \\ Myriam Southwell, Ph.D. \\ Universidad Nacional de La Plata, Argentina**
}

nicolaspatierno@gmail.com

\section{Resumen (analítico)}

El artículo se desprende de una investigación dedicada al análisis crítico de lo que suele ser referenciado como violencia escolar. La misma fue realizada en tres escuelas secundarias de la ciudad de La Plata, Argentina, entre los años 2011 y 2018 y pretende evidenciar, entre otras cuestiones, la influencia de los imaginarios sociales negativos sobre el modo en que los educadores suelen intervenir en la resolución de conflictos considerados (por ellos mismos) como violentos. Para llevar adelante esta tarea, se optó por una metodología de tipo cualitativa nutrida por el análisis de testimonios y el relevamiento de bibliografía especializada. La conclusión invita a repensar el lugar de la educación secundaria en la contención y el redireccionamiento de la violencia hacia una convivencia pacífica y democrática.

\section{Palabras clave}

Escuela secundaria, violencia, conflicto social, convivencia, consenso.

\section{Thesauro}

Tesauro de Ciencias Sociales de la Unesco.

\section{Para citar este artículo}

Patierno, N., \& Southwell, M. (2020). Desmitificando la violencia escolar: un análisis crítico de las representaciones. Revista Latinoamericana de Ciencias Sociales, Niñez y Juventud, 18(3), 1-29.

https://dx.doi.org/10.11600/1692715x.18309

\section{Historial}

Recibido: 21.10 .2019

Aceptado: 16.04.2020

Publicado: 25.08.2020

\section{Información artículo}

Este artículo es una síntesis de la investigación denominada La violencia (escolar) en cuestión: un estudio en escuelas secundarias públicas de la ciudad de La Plata. La realización de la misma contó con el financiamiento de dos becas: la primera (de iniciación), otorgada por la Universidad Nacional de La Plata (2014-2017) y la segunda (de finalización), por el Consejo Nacional de Investigaciones Científicas y Técnicas (2017-2019). Área: Ciencias Sociales; subárea: Educación. 


\section{Demystifying school violence: a critical analysis of representations}

\section{Abstract (analytical)}

This paper is based on a research focused on the analysis of what is usually referred to as school violence. It was carried out in three secondary schools in the city of La Plata, Argentina between 2011 and 2018 and intends to show the influence of negative social imaginaries on the way in which educators usually intervene in the resolution of conflicts considered (by themselves) to be violent. To carry out this task, a qualitative methodology was chosen that was supported by the analysis of testimonies and a review of specialized literature. The article concludes by inviting us to rethink the role of secondary education in the containment and redirection of violence towards a peaceful and democratic coexistence.

Keywords

High school, violence, social conflicto, coexistence, consensus.

\section{Desmistificando a violência escolar: uma análise crítica das representações}

\section{Resumo (analítico)}

Este artigo surge de uma pesquisa dedicada à análise do que geralmente é referenciado como violência escolar. Foi realizado em três escolas secundárias na cidade de La Plata, Argentina, entre 2011 e 2018 e pretende mostrar, entre outras questões, a influência dos imaginários sociais negativos sobre o modo nos quais os educadores costumam intervir na resolução de conflitos considerados (por si mesmos) como violentos. Para realizar esta tarefa, optou-se por uma metodologia qualitativa baseada na análise de depoimentos e a pesquisa de bibliografia especializada. A conclusão nos convida a repensar o lugar do ensino médio na contenção e no redirecionamento da violência para uma convivência e pacífica e democrática.

\section{Palavras-chave}

Escola secundária, violência, conflito social, convivência, consenso.

Información autores

[*] Doctor en Ciencias de la Educación (UNLP). Magíster en Educación Corporal (UNLP). Profesor en Educación Física (UNLP). Investigador asistente de la carrera de investigador científico del Conicet. Profesor en la Facultad de Humanidades y Ciencias de la Educación (UNLP). (iD) 0000-0002-3411-7309. H5: 2. Correo electrónico: nicolaspatierno@gmail.com

[**] Ph.D. del Departamento de Gobierno de la Universidad de Essex (Inglaterra). Magíster en Ciencias Sociales con orientación en Educación (Flacso Argentina). Profesora y licenciada en Ciencias de la Educación (Universidad Nacional de La Plata). Investigadora de la Carrera de Investigador Científico del Conicet. Profesora titular en la Facultad de Humanidades de la Universidad Nacional de La Plata. iD 0000-0001-5392-6606. H5: 13. Correo electrónico: islaesmeralda@gmail.com 


\section{Introducción}

esde hace dos o tres décadas, muchos educadores, basados en una gran canti-y de magnitud creciente - en el escenario escolar contemporáneo. Esta afirmación suele estar acompañada por el agregado de que quienes trabajamos regularmente en educación entendemos el significado de la violencia y confirmamos que es posible articular escuela y violencia en una misma oración. Esta peligrosa naturalización de supuestos ha llegado incluso a trascender el espacio específicamente escolar: la problemática comúnmente conocida como violencia escolar hoy no se restringe únicamente a la docencia y la investigación educativa, sino que - particularmente en los últimos tiempos- se ha instalado como un debate público. El problema se visibiliza en redes sociales, en programas radiales, en la televisión, en diarios, en revistas; pero, a pesar de que muy pocos dudan en afirmar que la violencia forma parte de la cotidianeidad escolar $-\mathrm{y}$ de acuerdo a los medios de comunicación, pareciera recrudecerse aún más en el nivel secundario-, en realidad nadie sabe bien cómo detallar este fenómeno, ni qué hacer al respecto.

Es preciso aclarar que esta construcción de la violencia escolar no refiere a los excesos en la aplicación de sanciones disciplinarias. La representación contemporánea de la violencia que irrumpe en la escuela, por el contrario, adopta un carácter multidireccional, involucrando a actores y situaciones que históricamente no formaban parte del paisaje escolar (Kaplan, 2015). A pesar de que las nuevas violencias, han llegado a naturalizarse tanto en el interior como en el exterior de las instituciones educativas, hay algo en dicha enunciación que resulta incómodo, contradictorio, perturbador. La investigación doctoral que respalda la realización del presente artículo intenta adentrarse justamente ahí, en la incomodidad resultante de unir escuela y violencia en una misma categoría.

Desde el aspecto etnográfico, la investigación referenciada incluye una serie entrevistas semiestructuradas enfocadas en las representaciones que tienen los educadores sobre el fenómeno —común y controversialmente-conocido como violencia escolar. En síntesis, 
la muestra estuvo compuesta por once informantes adultos con distintas funciones (docentes, directivos y equipos de orientación escolar) en tres escuelas secundarias públicas ubicadas en distintos barrios de la ciudad de La Plata, Provincia de Buenos Aires, Argentina.

En primer lugar, se seleccionó una escuela secundaria situada en el centro de la ciudad de La Plata, luego otra institución del mismo nivel educativo, pero separada de la primera por unos cinco kilómetros con dirección al norte y, por último, una tercer escuela también de nivel medio y emplazada en el partido de La Plata, pero alejada del casco urbano por unos diez kilómetros en dirección al noroeste, en una de las zonas donde operó el Ferrocarril Provincial (luego Ferrocarril General Belgrano). Dichas escuelas serán referenciadas de manera abreviada como escuela del centro, escuela de la periferia norte y escuela del barrio ferroviario.

La escuela del centro se caracteriza por estar situada a unas pocas cuadras del corazón del casco urbano de La Plata, es decir, la Plaza Moreno y sus edificios aledaños (dedicados a la administración y el gobierno del municipio y la Provincia de Buenos Aires). Debido a su locación urbana, esta institución cuenta con todos los servicios y con numerosos accesos en lo que refiere al transporte público. Por esta misma razón, el establecimiento recibe alumnos provenientes de barrios muy diversos - tanto del casco urbano como de la periferia-, lo que a su vez revela la presencia de una matrícula sumamente heterogénea. Así mismo, la escuela se encuentra rodeada por el principal centro comercial de la ciudad, lo que la sitúa en un lugar de constante tránsito peatonal y automovilístico y la deja vulnerable a interrupciones frecuentes en el tráfico y al sonido estruendoso que suele acompañar los reclamos y las movilizaciones que regularmente se concentran alrededor de sus calles. Desde el aspecto edilicio, la escuela evidencia claras muestras de deterioro como el desprendimiento de mampostería, filtraciones de agua y roturas en el mobiliario escolar (producido no solo por el uso corriente, sino también por el daño deliberado).

La escuela de la periferia norte, por su parte, también se encuentra ubicada en una zona urbanizada y de fácil acceso, aunque, si tomamos la escuela del centro como punto de referencia, la frecuencia del transporte público es significativamente menor. El barrio en el que se enmarca la institución, si bien cuenta con todos los servicios, muestra grandes diferencias en lo que respecta a la infraestructura de los hogares; es decir, en una misma manzana se pueden observar tanto casas humildes construidas con materiales precarios, como inmuebles costosos con más de una planta y varios accesos para vehículos. En cuanto a la disposición del espacio físico, la escuela comparte el sector de la entrada y el patio principal con una escuela primaria, situación que genera roces y desencuentros 
entre los diferentes miembros de la comunidad escolar. ${ }^{1}$ En cuanto a las instalaciones, el establecimiento revela un desgaste severo; situación que se agravó significativamente a partir de una inundación pluvial acontecida en el año 2013, afectando mayormente la situación estructural de las paredes y el funcionamiento de los baños.

La escuela del barrio ferroviario se enmarca en una zona semirural en cuyo contexto inmediato se entremezclan los restos de un predio que antiguamente funcionó como estación de trenes (actualmente en estado de abandono) con una serie de terrenos destinados al trabajo agrícola (fundamentalmente pequeñas parcelas con construcciones precarias). El colegio cuenta con luz y agua potable y con un único servicio de transporte público que lo comunica con el centro de La Plata (con una frecuencia considerablemente menor en comparación a las escuelas anteriormente descritas). El barrio cuenta con una delegación municipal y un centro comercial propio, lo que le otorga cierta autonomía en términos de administración, y posee una sola calle principal (la cual finaliza en la antigua estación). La limitada cantidad de accesos y la posibilidad de contar con una delegación municipal convierten a la zona en algo así como un pueblo o una localidad pequeña con un ritmo propio.

Más allá de las características propias de cada zona, si tomamos el nivel socioeconómico y la organización familiar como parámetro de referencia, nos atrevemos a afirmar que los rasgos generales de la población que asiste a las tres escuelas seleccionadas no poseen grandes variaciones. A estas instituciones suelen asistir los hijos de trabajadores en relación de dependencia - tanto pública como privada-, con escasos recursos y con un poder económico limitado. La diversidad de origen y de las actividades desarrolladas por las familias evidencian la presencia de poblaciones heterogéneas que, a pesar de sus diferencias, asisten a la escuela con las mismas dificultades: vivienda, alimentación, trabajo, salud, higiene y seguridad constituyen algunas las principales carencias de los sectores que asisten hoy a estos colegios.

\footnotetext{
${ }^{1}$ La disposición espacial prevista para los tres primeros años de la educación secundaria pública (división hasta hace poco denominada educación secundaria básica y actualmente conocida como ciclo básico), en muchos casos comenzó funcionando - y actualmente lo sigue haciendo- como una subdivisión dentro de un edificio originalmente dispuesto para el funcionamiento de una escuela primaria. Esta repartición de espacios (inaugurada en los años noventa a partir de la Ley Federal de Educación 24195), lejos de realizarse de manera gradual y planificada, condujo a un desconcierto entre las responsabilidades provinciales y nacionales en lo concerniente a la administración de las escuelas. Entre las consecuencias que se sucedieron a esta reforma, la superpoblación de estudiantes concentrados en establecimientos con una capacidad limitada fue una de las constantes que, lejos de resolverse, pareciera haberse recrudecido con el paso de los años. En suma, la convivencia de alumnos, docentes y autoridades de diversos niveles educativos bajo el mismo techo genera, cotidianamente, varios conflictos mayormente producidos por la saturación de los espacios físicos y por numerosas confusiones a la hora de asumir responsabilidades.
} 


\section{Violencia escolar: contradicciones de una}

\section{representación estigmatizante}

En el concepto violencia escolar colisionan dos tendencias históricamente antagónicas en los debates educativos: por un lado tenemos a la escuela, la institución donde se reúne y se socializa a las nuevas generaciones; el primer lugar fuera de la familia dónde los jóvenes comienzan a reconocer la presencia de otros miembros de la sociedad (Pineau, 2008). Con fines analíticos, a esta representación la denominaremos optimista, porque parte de la premisa de que la escuela es capaz de contener y redirigir los comportamientos violentos hacia actividades legítimas; o, en otras palabras, podría decirse que la escuela invierte recursos para que los jóvenes, progresivamente, sean capaces de sustituir las manifestaciones agresivas por otras ligadas a un orden simbólico.

La segunda tendencia se enfoca en la exacerbación de la violencia; un concepto que, por su carácter relacional, situacional y cambiante resulta muy difícil de definir, pero que, siguiendo a Garriga-Zucal (2016), ineludiblemente conlleva una fuerte carga social negativa. Si bien su significado puede variar, no suele ocurrir lo mismo con su percepción. En un diálogo referido a la violencia, el receptor puede entender algo distinto a lo que intenta transmitir el emisor (de hecho es muy poco probable que dos personas interpreten la violencia de igual modo); no obstante, tanto el emisor como el receptor probablemente acuerden en que la violencia refiere a algo malo, peligroso e indeseable. Por lo tanto, la introducción de la violencia en el ámbito escolar representa, en términos históricos, una novedad y al mismo tiempo una contradicción; o, en términos de Duschatzky y Corea (2013), un «fuera de lugar, una irrupción que resulta inconsistente con la representación de una escuela» (p. 28). A esta tendencia la denominaremos fatalista, porque se percibe a la escuela como un lugar altamente beligerante en el cual los estallidos violentos serían generados por elementos propios del dispositivo escolar (el accionar de los docentes, la conducta de los alumnos, los procesos de evaluación, etcétera). Es preciso añadir que este modo de ver - y estigmatizar - la escuela se encuentra fuertemente influenciado por el discurso alarmista y sensacionalista de los medios masivos de comunicación. Al abordar la problemática, estos «enuncian a la violencia escolar con una contundencia y precisión que pareciera tratarse de un fenómeno terminante, indiscutible, que no amerita ningún tipo de explicación» (Brener \& Kaplan, 2015, p. 80). Recordemos que el riesgo de este tipo de representaciones se encuentra en su naturalización, es decir, cuando una categoría socialmente reproducida es considerada parte ineludible de la realidad. De acuerdo a García-Villanueva (y otros): «representar un objeto significa construir- 
lo simbólicamente para lograr que tenga sentido en quien lo representa» (2012, p. 498). Siguiendo esta línea, podría decirse que en la construcción violencia escolar las representaciones negativas que envuelven al primer término, inevitablemente van afectar el segundo.

\section{La representación optimista de la escuela en el}

\section{proceso de renuncia a la violencia}

Centrando la atención en la primera de las tendencias descritas más arriba, a continuación analizaremos diversos testimonios y documentos a fin de indagar aquellos elementos por los que - históricamente- se consideró a la escuela como un ámbito propicio para la socialización y, por añadidura, para la renuncia a la violencia. Siguiendo a Pineau (2008), la representación de la escuela como el lugar previsto para el aprendizaje de la no-violencia se fusiona con una concepción de la institución educativa como aquella institución —originada en la modernidad_- para la construcción y la reproducción de un modelo ideal de hombre; un sujeto «único, esencial, preexistente, soberano, completo, compacto, racional, planificador, activo, autocentrado, limitado, idéntico a sí mismo, etc.» (Pineau, 2008, p. 86).

La violencia, en tanto construcción social cargada de valoraciones negativas, estuvo históricamente asociada a cierta animalidad o comportamiento primitivo, cualidades que fueron consideradas indeseables y obstaculizantes para el desarrollo del proceso civilizatorio; un proceso específicamente moderno que, de hecho, se construyó a la par de la escuela. «El hombre proviene de la naturaleza, de la animalidad, del azar, de la contingencia, etc., pero debe alejarse de allí, debe desprenderse de esos elementos para surgir puro y limpio y poder expandir y difundir su razón» (Pineau, 2008, p. 87). Con el fin de aplacar estas conductas naturales o esenciales, se implementaron una serie de dispositivos que varían desde el autocontrol — producto de la influencia de una moral colectiva- 
hasta la penalización externa, materializada en las instituciones educativas a través de las sanciones disciplinarias (eventualmente, acompañadas por el uso de la fuerza). ${ }^{2}$

La escuela moderna replicó algunas características propias de la matriz monacal y las reescribió de acuerdo a la lógica de la época. En ese esquema, las paredes que delimitaban el adentro y el afuera de la institución estaban cargadas de un fuerte simbolismo: en el adentro se debía resguardar todo lo bueno de la amenaza que representaba el exterior, lugar de la incertidumbre y la maldad (el peligro, la incivilización, la delincuencia, la inmoralidad, los malos hábitos, etcétera). Replicando - y acentuando- la represión del cristianismo al uso individual de la fuerza, la violencia fue ocupando un lugar de exterioridad con relación a la institución educativa.

La escuela se convierte en la caja donde se conserva algo positivo de los ataques del exterior negativo y desde ella debe expandirse para dominarlo. La escuela, templo de la salud, de la civilización, de la Patria, de la tradición, de la razón, de la ciencia, de lo público, conserva e irradia estos bienes sobre el exterior, reino de la enfermedad, de la barbarie, de la antipatria, de la novedad, de la irracionalidad y el azar, del saber no-científico, de la ley de la selva. (Pineau, 2008, p. 92)

\footnotetext{
${ }^{2}$ Desde un punto de vista educativo-moderno-tradicional, la violencia impartida en las escuelas como parte de una sanción disciplinaria era considerada un acto legítimo. La legitimidad descansaba en el convencimiento generalizado de que en la escuela se debía fabricar, con los medios que fueran necesarios, el modelo de hombre ideal descripto en el texto principal. Parafraseando a Hegel (1968), el ejercicio de la violencia en el ámbito de la educación escolarizada no solo posee fines correctivos, sino que forma parte del propio acto educativo. A diferencia de la violencia secundaria, impartida por el Estado para aplacar las resistencias individuales, según el filósofo mencionado el empleo de la violencia en las escuelas poseía un carácter primario. En otras palabras: dado que el fin último de la violencia institucional conduciría a un apaciguamiento de la sociedad, su uso - aun en las edades más tempranas- era considerado fundador de un orden social. La fuerza en manos de la autoridad escolar tenía como objetivo aplacar la violencia primordial u original ligada al desconocimiento y la ignorancia; como dijimos, su empleo no solo era considerado legítimo, sino también indispensable. Resumiendo, para Hegel la educación no puede llevarse a cabo sin violencia pedagógica, y para que esto suceda es necesario, primero, vencer cierta resistencia natural (ligada a la representación de un mundo desregulado, es decir, carente de restricciones y obligaciones).
} 
Hoy en día, esta caracterización de la escuela como institución socializadora y pacificadora - aunque con ciertos signos de debilitamiento- se sigue sosteniendo (Dussel, 2005). ${ }^{3}$ Si bien no representa la totalidad de las opiniones encontradas, un significativo número de docentes y autoridades entrevistados — posicionados desde lo que podría considerarse un deber ser- se refieren a la institución en estos términos; es decir, evidenciando la permanencia, al menos en el plano discursivo, de ciertas representaciones asociadas a la transmisión de la no-violencia. A continuación seleccionamos algunos fragmentos extraídos de tres entrevistas realizadas a una integrante de un equipo distrital de infancia y adolescencia, un profesor de Construcción de la Ciudadanía (perteneciente a la escuela del centro) y un preceptor (con funciones en la escuela del barrio ferroviario):

Si el conflicto es inherente al ser humano, la educación es el antídoto para poder regular los vínculos; y lo produce en grandes masas porque lo produce en Argentina como estado (...). Uno escucha «la escuela está cada vez peor», y en realidad nosotros pensamos que es al revés. Los chicos van a estar atravesados por cuestiones simbólicas que nosotros no tuvimos; en nuestras épocas no había centros de estudiantes, no teníamos espacios de exposición ni espacios de voz, no podíamos decir lo que nosotros pensábamos (...). En realidad la escuela sigue sosteniéndose, y la verdad que es la mejor forma de educar.

Si algo tiene como objetivo nuestra escuela es educar para la paz, entonces todas las situaciones se van a hablar y a escuchar.

La escuela puede sacar buena gente o mala gente. Yo prefiero que la escuela saque buena gente. Y hay que colaborar en eso. ¿Por qué? Porque esa buena gente o mala gente el día de mañana se va a cruzar con mi hija, por ejemplo (...). Yo sé que puedo hacer algo en ese lugar, en las escuelas. Para el día de mañana sacar buenos pibes y no delincuentes.

\footnotetext{
${ }^{3}$ Sobre el papel de la escuela como institución prevista para la socialización y la pacificación, consideramos oportuno atender los aportes de Dussel, quien afirma que, si bien su hegemonía muestra claros signos de crisis, esta institución aún perdura - sobre todo en el plano discursivo- como un lugar indispensable para la transmisión de cierto orden disciplinario, materializado en «la cultura política educativa y en las formas en que se piensa la convivencia, el disenso y el conflicto en las escuelas» (2005, p. 1110). La misma autora también advierte que, si bien esta función se mantiene intacta en los discursos educativos, «esto no es lo que efectivamente sucede en las escuelas» (Dussel, 2005). Este desencuentro entre lo que se dice y lo que ciertamente acontece en los colegios en materia de convivencia, es una constante que se advirtió en muchas de las entrevistas realizadas a directivos y docentes. Al mismo tiempo que varios de estos agentes se pronunciaron en reiteradas ocasiones como impulsores de, en sus propios términos, una educación democrática o una educación para la paz, también reconocieron - generalmente asumiendo una postura conservadora en la descripción de los acontecimientos_la presencia constante de conflictos señalados como violentos. Creemos que este tipo de contradicciones nos obliga a reflexionar una y otra vez sobre las confusiones y las arbitrariedades que suelen rodear la temática en cuestión.
} 
En los últimos años, la caracterización de la escuela como lugar de la civilización y la pacificación se ha entrelazado a menudo con paradigmas político-educativos vinculados en algún punto con la democracia y la inclusión. Estas tendencias repercutieron de manera directa en las medidas que debían tomarse para analizar y resolver los problemas comúnmente asociados a la violencia. De un tradicional enfoque penalizante y estigmatizador se pasó a una orientación más reflexiva (Dussel, 2005), centrada en la contextualización de los problemas. Poco a poco, la atención comenzó a dirigirse hacia los elementos desencadenantes y hacia las condiciones del entorno. En este sentido, varios estudios realizados a mediados de la década pasada intentaron mostrar que la idea de convivencia es superadora de la disciplina en términos de derechos educativos. Mientras que la disciplina históricamente fue utilizada como instrumento para señalar acciones como buenas o malas, correctas o incorrectas, bajo el paradigma de la convivencia se intenta desarrollar una concepción «más amplia que hace referencia a los modos de estar junto con otros y a la manera en la que es transitada esta experiencia» (Nuñez, 2015, p. 66).

Estos nuevos modos de interpretar los conflictos e intervenir sobre ellos introdujeron $-\mathrm{y}$ pusieron en el centro de la escena- la preocupación por el contexto, es decir, la consideración de los vínculos familiares, los problemas barriales, las relaciones intergeneracionales y el clima escolar. ${ }^{4}$ De esta manera, una amonestación, un cambio de turno, una suspensión o una expulsión, no solo fueron consideradas medidas obsoletas e ineficaces, sino que a partir de la nueva Ley de Educación Nacional (Argentina) pasaron a constituir medidas antirreglamentarias. Desde el punto de vista de Dussel (2005), actualmente asistimos a un «desplazamiento de las formas disciplinarias centradas en la autoridad burocrático-legal a formas reflexivas (...), fundadas en discursos psicopedagógicos y en la idea de contrato o negociación con los niños y jóvenes» (p. 1110). Sobre este pasaje de un tratamiento individual de la violencia a una interpretación considerablemente más amplia, democrática y contextualizada, Kornblit (2008) manifiesta:

\footnotetext{
${ }^{4}$ Cornejo y Redondo (2001) definen el clima escolar como «la percepción que tienen los sujetos acerca de las relaciones interpersonales que establecen en el contexto escolar (a nivel de aula o de centro) y el contexto o marco en el cual estas interacciones se dan» (p. 5). Varias investigaciones referidas a la violencia en las escuelas suelen incluir la influencia del clima escolar o el clima institucional como uno de los factores determinantes en el desencadenamiento de conflictos violentos. Entre estos estudios se destaca el desarrollado por D’Angelo y Fernández, publicado con el título Clima, conflictos y violencia en las escuelas (2011), en el que afirman que «la cuestión de los climas escolares ocupa un lugar central en las investigaciones sobre la violencia en las escuelas, en la medida en que permite desmarcarse de los determinismos fatalistas y comenzar a interrogarse sobre la posibilidad de una intervención activa de la institución escolar en relación con la gestión del conflicto y la violencia» (p. 23).
} 
Los intentos de dar cuenta de estos procesos desde el campo académico atravesaron un camino desde el énfasis puesto en los problemas individuales de los alumnos, en cuanto a sus características personales y familiares - discurso que abrevaba en la impronta de la psicología en las ciencias de la educación-, a enfoques socioculturales que toman en cuenta tanto el proceso de los factores estructurales en la vida escolar como los psicosociales. (pp. 11-12)

En algunos discursos de los adultos entrevistados fue posible rastrear - en ocasiones con matices contradictorios - algunas referencias a lo que podría considerarse nuevos enfoques o nuevos paradigmas en materia de resolución de conflictos. En esta línea, consideramos pertinente atender a las siguientes opiniones:

Hay que tratar de entender más a los jóvenes, porque si nos quedamos con la sentencia de que fulano es irrespetuoso, consume, es un violento... Y si nos quedamos solo con eso estamos en el horno. Hay que tratar de tener una mirada más crítica. Bueno, a ver, qué le estará pasando a este alumno, qué está sucediendo en la vida de este joven que hace que actúe así. Porque si nos quedamos con lo que vemos, con la apariencia, con el joven violento, con el que consume, con el que insulta, con el inquieto..., ahí es imposible hacer algo. (Integrante del equipo de orientación escolar de la escuela de la periferia norte)

El proceso social se supone que en la primaria ya se está trabajando; el chico aprende a compartir, aprende a convivir, va adquiriendo hábitos. Entonces, si acá hubo un momento de tensión y estrés hay que hablarlo y hay que trabajarlo, pero no sacarlo (...). Si vos sacas a un chico de la escuela estás vulnerando el derecho a la educación que es primario; es como comer. (Vicedirectora perteneciente a la escuela del barrio ferroviario)

Yo creo que la sanción por sí misma, sin el diálogo, sin la reflexión, sin la búsqueda de nuevos acuerdos y sin la posibilidad de una reflexión escrita, una reflexión con la familia, es absolutamente obsoleta, no tiene sentido (...). Por eso siempre hablamos de sanciones reparadoras, o de restitución de acuerdos o de búsqueda de información. En ningún momento hablamos de expulsión. (Directora perteneciente a la escuela del barrio ferroviario)

En lugar de sentenciar y quedarse con las apariencias, la integrante del equipo de orientación escolar propone desarrollar una mirada crítica, esto es, adentrarse en la vida del joven para indagar lo que le sucede, lo que lo perturba, lo que lo intranquiliza. En otras palabras, la propuesta se centra alrededor de la pregunta: ¿qué es lo que acontece en la vida de un joven, fundamentalmente en la relación que tiene con su familia, la escuela y sus pares para que este se haya visto tentado a hacer uso de la violencia?

Estos nuevos enfoques, más orientados a proteger al alumno que a castigarlo con una sanción penalizante, se erigen sobre la presunción de que las medidas disciplinarias tradi- 
cionales no solo no evidencian avances en la mitigación de los hechos comúnmente considerados violentos, sino que además atentan contra los derechos de los jóvenes. Es preciso aclarar que este nuevo paradigma en lo que refiere al tratamiento de la violencia en escenarios escolares, lejos de reducirse a una experiencia aislada o a una moda pasajera, se materializó en diversas normativas, protocolos y guías de carácter oficial, en concordancia con las políticas públicas condensadas en la Ley 26206 de Educación Nacional (Argentina).

Ahora bien, como ocurre con toda reforma, estos modos más democráticos de tratar de resolver los conflictos, si bien evidenciaron un importante avance en lo que respecta al cuidado y la garantía de los derechos humanos y los derechos de los niños, también desencadenaron algunas resistencias y confusiones a la hora de determinar qué hacer en materia de convivencia escolar. En un estudio desarrollado por Litichever (2012) sobre las normas de convivencia en varias escuelas secundarias de Argentina, es posible advertir que la indecisión, la confusión o el temor de los adultos por no saber qué hacer frente a las problemáticas más frecuentemente visibilizadas en los últimos tiempos (agresiones físicas, portación de armas, consumos problemáticos, conflicto con la ley, contravenciones, entre otras), suele advertirse en el contenido - explícito e implícito- de los reglamentos de convivencia. Conjuntamente con una serie de mandatos históricamente asociados a la regulación de la cultura escolar (como la apariencia, el cuidado de la institución y el respeto por los símbolos patrios), estos documentos - más exactamente aquellos confeccionados entre la década del noventa y la actualidad- dejan traslucir la permanencia - y la naturalización- de varios temores por parte de los educadores. En palabras de Litichever (2012):

En la letra de los reglamentos se incorporan nuevas temáticas (...), lo que indica la presunción, por parte de los actores institucionales de que, en un momento u otro, ocurrirán. La percepción de los docentes, preceptores y equipo directivo de que los alumnos pueden desplegar una serie de transgresiones novedosas, más allá de que efectivamente las realicen, lleva a plantear las interacciones de manera diferente. (p. 7 )

Siguiendo esta línea, podría decirse que los reglamentos de convivencia representarían algo así como un reflejo o la materialización de las demandas y las expectativas que los adultos construyen sobre los jóvenes (sobre todo en relación a las problemáticas más resonantes de los últimos tiempos). De esta manera, asentándose sobre el mandato histórico de que la escuela es el lugar ideal para transmitir el rechazo a la violencia, muchos docentes y directivos encuentran en estos documentos un espacio para plasmar, no solo 
cuestiones vinculadas con la convivencia, sino también una serie de valoraciones que podrían leerse como preconceptos y estigmatizaciones derivadas de un clima de época atravesado por cierta paranoia y por la presunción de que las poblaciones jóvenes son más proclives a cometer actos ilegales. ${ }^{5}$ Así, resulta significativo el hecho de que

en las escuelas que atienden a sectores populares se concentran con mayor preponderancia en sus reglamentos normas para neotransgresiones que refieren a la violencia, la delincuencia y allí se enuncian pautas en relación a la prohibición de ingresar con armas y otras vinculadas a los robos. En la enunciación de este tipo de normas parecen operar los efectos de una serie de supuestos y expectativas de los agentes escolares respecto de los barrios populares en los que se ubican las escuelas sobre la percepción de peligrosidad extrema. (Litichever, 2012, p. 8)

El contenido de estas reglamentaciones, siguiendo la línea de Litichever (2012; Litichever et al., 2008), nos permite vislumbrar una serie de constantes - inmiscuidas entre cuestiones procedimentales inherentes a la cotidianeidad de las instituciones - tendientes a la naturalización de ciertas idealizaciones y expectativas vinculadas con lo aquí hemos decidido nombrar una representación optimista de la escuela.

\section{La representación fatalista de la escuela y la (supuesta) generación de violencia}

En contraposición a la caracterización de la escuela como aquel lugar favorable para transmitir valores asociados a la civilización y la pacificación, en los últimos tiempos es posible advertir la presencia cada vez mayor de cierta concepción fatalista de la misma. Esta nueva tendencia parte de la premisa de que la institución educativa, y más aún el

5 En línea con lo que podría caracterizarse, sintéticamente, como una mirada sesgada de la juventud, consideramos pertinente atender brevemente a los aportes de Chaves (2010) y Núñez (2015). A partir de una serie de investigaciones enfocadas en la discriminación en el nivel secundario, particularmente en la asignación de ciertos rótulos o etiquetas, Núñez advierte que el señalamiento de, por ejemplo, el desertor o el libre, en lugar de promover la asistencia a clases, recrudece aún más el problema original, ya que introduce una fuerte carga social negativa (legitimada en la valoración positiva del sacrificio y la meritocracia). Chaves, por su parte, pone el acento sobre los efectos nocivos de la vulnerabilidad. Esta circunstancia, en ocasiones materializada en la percepción de algún tipo de subsidio personal o familiar, cristaliza una serie de representaciones negativas sobre los jóvenes señalados como pobres o vulnerables que los sitúan en un lugar de negatividad de sus posibilidades. En resumen, podríamos decir que la estigmatización de los jóvenes en edad escolar es un ejercicio — a veces inconsciente- que se nutre de una serie de preconceptos cargados con una fuerte connotación negativa. Lejos de tratarse de un asunto menor, creemos que esta situación repercute directamente sobre el problema de la violencia, ya que este tipo de caracterizaciones — de manera más o menos explícita- favorece el establecimiento de un clima sesgado por la desconfianza y el distanciamiento. 
nivel secundario, se ha convertido en un lugar donde predomina el descontrol y la violencia. Dicha concepción se fundamenta, en términos generales, en una profunda crisis que afectaría -simbólica y materialmente- el modelo de la escuela moderna-tradicional. Según Southwell et al. (2015):

En los últimos años, la situación de la escuela media ha sido objeto de innumerables debates. Los diagnósticos más extendidos, con amplia repercusión en los medios de comunicación, hacen referencia a su pérdida de funciones, que la alejaría de sus mandatos fundacionales. (p. 311)

Esta caracterización fatalista no solo parte de la creencia de que la escuela ya no representa lo que históricamente representó en materia de educación y cuidado de las nuevas generaciones; además, incorpora la violencia como un problema evidente, dado e incuestionable. En esta línea, Duschatzky y Corea (2013) afirman que «la escuela sabe - mejor dicho, supo- mucho de los tiempos estables, regulares y de progreso. Supo de ello porque fue creada en tiempos estables, en condiciones regulares, y para asegurar el progreso. Pero no se trata de eso ahora» (p. g).

El ejemplo más representativo de esta visión fatalista de la escuela posiblemente se encuentre en las caracterizaciones realizadas por los medios de comunicación, más específicamente, en las dramáticas coberturas que suelen hacer de los casos comúnmente asociados a la violencia. Esta situación ha sido advertida por varios autores dedicados a la problemática desarrollada (Bleichmar, 2008; D’Angelo \& Fernández, 2011; Kaplan, 2015; Kornblit, 2008, entre otros); sus investigaciones, por lo general, coinciden en considerar a los medios como un elemento clave en la reiteración, magnificación y, en cierta forma, en la misma creación del —debatible— concepto violencia escolar. Tal como afirman Brener y Kaplan (2015):

La violencia escolar se ha transformado en una suerte de categoría dada: prácticamente se ha constituido en una sección autónoma de periódicos gráficos, revistas de circulación masiva, en columnas de numerosos periodistas televisivos, así como en preocupación constante de columnistas y formadores de opinión de emisoras radiales. De este modo, empieza a no resultar tan excepcional que la vida escolar esté atravesada por imágenes que parecían ser exclusivas de otros espacios sociales. (p. 81)

Esta cosificación de la violencia escolar favorece la reproducción de cierta paranoia social que recae, indiscriminadamente, sobre todo lo que remite en algún punto a las rela- 
ciones mediadas por lo escolar, afectando determinantemente el valor simbólico de la escuela media en nuestro territorio. Parafraseando a Southwell (2018), la violentación de la escuela secundaria se alinea a una serie de críticas relacionadas (rastreables desde mediados del siglo XX) que deben ser revisadas, no solamente en su validez, sino también en sus efectos destructivos sobre el valor simbólico del sistema educativo público.

Lejos de reducirse a unos pocos periódicos o medios televisivos, la caracterización fatalista de la escuela (sobre todo en las instituciones de nivel secundario) se replica cada vez con más recurrencia en la opinión pública; en ocasiones, son los propios educadores quienes revelan la presencia de un discurso alarmista sobre la violencia. En sus términos:

El contenido de los noticieros en un noventa por ciento de violencia, que no deja de ser la realidad. Lo que hay que revertir es eso, y la mirada ante eso, para que no sea una cosa cotidiana y normal (...). Me parece que los medios magnifican. Las cosas pasan, pasaron siempre, pasan en todos lados y en todo el mundo. Hemos visto que un chico puede entrar a una escuela de Estados Unidos con un arma y mata a diez pibes. Entonces no me vengan con que es acá, con que es en la provincia de Buenos Aires. (Vicedirectora, escuela de la periferia norte)

Programas de violencia callejera, programas de violencia entre adolescentes, el empoderamiento del macho frente a la mujer, frente al otro macho, el golpe como una búsqueda de solución al conflicto..., son cosas que están presentes en la mayoría de los programas de televisión. (Directora, escuela del barrio ferroviario)

Los medios están todo el día bombardeando. El tema es que muestran mucho; muestran la misma noticia una y otra vez. Te la pasan, te la recontra vuelven a pasar y te la vuelven a pasar (...). Están todo el tiempo mostrándote violencia, violencia, violencia. (Preceptora, escuela de la periferia norte)

En el relato de la vicedirectora es posible entrever la pregnancia de un recurso lingüístico característico de los medios de comunicación: la referencia a otros casos - acontecidos en otros tiempos o en otras regiones geográficas- con el fin de dramatizar o recrudecer la información original. Si bien la vicedirectora reconoce que el asunto de la violencia es un tema recurrente en los medios de comunicación (en sus propios términos, «que los medios magnifican»), a la hora de emitir una opinión propia sobre los problemas comúnmente asociados a la violencia en la escuela donde ella trabaja, hace una referencia a las masacres escolares de Estados Unidos como parámetro para medir los alcances y la frecuencia de los acontecimientos ocurridos en su colegio.

La caracterización fatalista de la escuela lleva ínsito un problema de carácter filosófico: si anteponemos la imposibilidad como rasgo predominante al problema de la violen- 
cia, la escuela nunca será capaz de resolver o atenuar ninguna clase de conflicto. Lejos de tratarse de un asunto de menor importancia, esta supuesta inutilidad de la institución educativa pone de relieve los efectos nocivos de cierta representación catastrófica. Dicho de otro modo, si la escuela nada puede hacer para mitigar los hechos comúnmente catalogados como violentos, entonces el problema de la violencia constituye la cara visible de un asunto considerablemente más grave, como es la propia legitimación de la escuela pública.

Como muchos docentes y autoridades entrevistados no confían en que la escuela en la que trabajan posea recursos para mitigar los conflictos violentos; entonces optan por asumir una posición de espectadores-críticos: culpan al sistema, a los inspectores, a los directivos, a los alumnos, a los padres, a los ministros, a sus colegas, etcétera. Siguiendo esta línea, consideramos oportuno preguntarnos: ¿cómo es posible que docentes y autoridades convivan a diario con un malestar generalizado sin hacer nada al respecto?, ¿qué sucede cuando alguien pretende hacer algo en relación al asunto de la violencia?, ¿de qué herramientas dispone?, ¿con qué obstáculos suele encontrarse?, ¿qué respaldo tiene?

\section{La perspectiva de los educadores}

En una investigación enfocada en la búsqueda de mecanismos pedagógicos para promover interacciones sin violencia, Páez-Martínez (2009) advirtió que los educadores seleccionados para su estudio casi nunca se preguntaban por su rol en las situaciones catalogadas como violentas. En ese marco, la autora hace una reflexión que consideramos pertinente citar: «Solemos mirar en la distancia la experiencia de las personas menores como si fuese suya y no nuestra, desconociendo tal vez que las personas adultas podemos renovarnos por el impulso hacia un nuevo comienzo» (p. 1004). Creemos que este tipo de análisis sirven para repensar el compromiso y la responsabilidad que ineludiblemente recae sobre los educadores al momento de enseñar la no-violencia. Ampliando, entendemos que la sustitución del pasaje al acto por mecanismos simbólicos no puede efectuarse sin la intervención de un tercero con recursos adecuados para buscar alternativas pacíficas. Ahora bien, retomando los interrogantes planteados más arriba, para que tales demandas puedan efectivizarse, las escuelas deberían disponer espacios previstos para la escucha y el diálogo. En este sentido, creemos que —al menos en los establecimientos estudiados-, las sugerencias realizadas por los docentes en relación al problema de la violencia en general fueron adecuadas y oportunas. 
Siguiendo con nuestra investigación, de acuerdo al testimonio de varios educadores, no podemos negar la permanencia de ciertos elementos obstaculizantes para el tratamiento de las diversas problemáticas que suelen acontecer en las escuelas seleccionadas. Entre las categorías más reiteradas se pueden distinguir el exceso de burocracia y la vorágine escolar, además de otras menos recurrentes pero igualmente preocupantes, tales como: 1a evasión, el desentendimiento, la falta de medios, la ambigüedad de ciertos discursos y las presiones externas a la institución. Con tales impedimentos es admisible que alguien -más allá de la función que desempeñe - se sienta superado por las circunstancias y no sepa cómo -o no desee involucrarse - en intentar mejorar el clima de su lugar habitual de trabajo.

Profundizando el análisis de esta cuestión, advertimos que muchos adultos entrevistados se manifestaron en descontento con respecto a las normativas disponibles para el tratamiento de la violencia en contextos escolares. Con fines analíticos, condensamos estas críticas en tres grupos: insuficiencia, irrelevancia y alteración.

\section{Insuficiencia}

Muchos de los entrevistados caracterizan a las normas previstas para la resolución de situaciones conflictivas como débiles, flojas o poco contundentes. Entre los documentos a los que se suele hacer referencia se destacan: la Guía de orientación para la intervención en situaciones conflictivas y de vulneración de derechos en el escenario escolar, el Programa de reformulación de normas de convivencia y disciplina y la propia Ley 26206 de Educación Nacional (Argentina). Una de las constantes que puede trazarse en el discurso de varios informantes adultos es la falta o la insuficiencia de instancias y organismos que deberían acompañar la puesta en marcha de las normativas mencionadas. En ocasiones estas demandas se entremezclan con una especie de nostalgia o reivindicación de los antiguos sistemas de sanciones (basados en amonestaciones, suspensiones y expulsiones). La expresión de estos reclamos se suele centrar en el supuesto - hoy antirreglamentario- de que tales normativas, por contemplar cierta dureza, eran más efectivas a la hora de tratar asuntos vinculados con la violencia. Entre las críticas relevadas se destacan las siguientes:

Las faltas existen y están dentro del acuerdo de convivencia; lo que no está definido es la máxima, le falta, está incompleto (...). Todo se centra ahora en el código institucional. A mí me gustaría que vos lo revises y veas que hay puntos en el código institucional que se que- 
dan sin respuesta frente a hechos de violencia, porque te quedás sin herramientas. (Profesor en Construcción de la Ciudadanía, escuela del centro)

Expulsiones no hay, pero para mí tendría que haber. A mí me pueden decir «vos sos un hijo de puta porque no estás incluyendo nada; a vos no te importa sacar a un pibe de la escuela». Yo prefiero sacar uno y que no se me vayan diez (...). Muchos buenos pibes se fueron por el tema de la droga. Entonces no me sirve seguir reteniendo gente; yo prefiero el sistema antiguo de expulsión (...); que el pibe sienta que perdió algo, que al padre se le complique la vida. Y yo no te digo que esto es una solución; esto es sacarse un problema de encima también. Pero yo prefiero sacarme un problema de encima a que se me vayan cinco o seis buenos. (Preceptor, escuela del barrio ferroviario)

Como muestra el segundo testimonio, esta demanda por sanciones más determinantes coexiste en ocasiones con el temor de evidenciar un posicionamiento autoritario o excluyente que exhiba tal rasgo públicamente o que ponga en juego su continuidad laboral. Este posicionamiento crítico - pero cauto al mismo tiempo- da cuenta de la presencia de ciertas confusiones respecto a la aplicabilidad y efectividad de las medidas reparatorias (vigentes en el período relevado). Provisoriamente, podemos decir que esta (supuesta) falta de instancias institucionales - que deberían acompañar la ejecución de las ordenanzas antes mencionadas- posiblemente se corresponda con el carácter novedoso y rupturista de las políticas proteccionistas de niños y adolescentes. Además de eso, la aplicabilidad de estas nuevas ideas se desarrolló sobre la base un sistema educativo pensado y diseñado en el siglo XIX, cuya estructura, si bien tuvo su momento de esplendor adentrado el siglo XXI, muestra inocultables contradicciones en el tratamiento de situaciones conflictivas. ${ }^{6}$

\section{Irrelevancia}

Otra constante que se evidencia en la opinión de los entrevistados adultos es que la redacción y la publicación de las normas escolares no suelen estar acompañadas por un acuerdo generalizado a la hora de determinar cuándo y cómo ponerlas en práctica. Así, aunque no desconocen el hecho de que la escuela está regulada por ciertas reglas (comúnmente plasmadas en los acuerdos de convivencia), varios educadores manifestaron que estos documentos, por lo general, no son respetados.

\footnotetext{
${ }^{6}$ Estas contradicciones se centran en el carácter excluyente de las antiguas medidas disciplinarias. La suspensión y la expulsión (aunque hoy en día se siguen aplicando a través de una manipulación corrupta de las reglamentaciones) atentan contra el derecho a la educación, una de las máximas presentes en numerosos tratados internacionales y en la Ley 26206 de Educación Nacional (Argentina).
} 
Centrando la atención en el interior de las instituciones educativas seleccionadas, el relato de varios adultos, no solo da cuenta de la irrelevancia de las normas, sino que en ocasiones también evidencia una desacreditación explícita de las mismas:

Los directivos toman el reglamento como ellos quieren. Hay algunos que se juegan y otros que no. (Preceptor, escuela del barrio ferroviario)

Para nosotros es importante que los Acuerdos Institucionales de Convivencia funcionen. Supuestamente acá ya hay acuerdos pero..., creo que se hicieron hace dos años atrás, ¿no? (...). Cuando le preguntamos a los chicos, no tenían idea de los acuerdos. (...) Y lo ideal de los acuerdos es que participen también las familias y toda la comunidad educativa. Por ahí eso es lo más difícil. Pero bueno, deberían ser trabajados así. (Integrante del equipo de orientación escolar de la escuela de la periferia norte)

A fin de evitar generalizaciones, en este punto es necesario aclarar que, si bien en las escuelas relevadas no pudo evidenciarse (al menos en la voz de los adultos) un funcionamiento claro de los Acuerdos Institucionales de Convivencia, no se desconoce el hecho de que en otras instituciones del mismo nivel y gestión estos acuerdos no solo se hallan contemplados desde un punto de vista institucional, sino que además operan, efectivamente, como consensos constituidos por los diversos agentes escolares. En este punto se destaca el testimonio de una vicedirectora quien, a modo de excepción, hizo referencia al funcionamiento de dichos acuerdos con cierta coherencia y apegándose a la normativa original:

Si se trabaja con la familia, si se trabaja con los alumnos, las cosas tienen que volver a su cauce; además, todos tienen que ver que uno se preocupa por ellos, que habla con ellos y que, si se tiene que aplicar una sanción, se aplica. Está en nuestro acuerdo de convivencia, donde dice que nosotros tenemos faltas leves y faltas graves. Esas faltas tienen diferentes tipos de sanción. Esa sanción puede ser una suspensión de dos días y también puede ser que si un alumno tiene reiteradas sanciones se forme un consejo de convivencia. (Vicedirectora, escuela del centro)

\section{Alteración}

Una de las irregularidades que pueden rastrearse a partir del análisis de los testimonios obtenidos en las entrevistas se centra en la manipulación o alteración de las normas existentes. Esta apropiación intencionada de los reglamentos evidencia la falta de supervisión o de seguimiento en lo que refiere a la aplicación de los mismos. El Estado consi- 
dera que la emisión de textos es suficiente, pero en la cotidianeidad escolar estos documentos son reinterpretados con un arbitrio y una parcialidad considerables.

En lugar de atender a la información provista por los documentos destinados al ordenamiento de la convivencia escolar y la resolución de conflictos, muchos docentes, autoridades y miembros de equipo de orientación escolar optan por introducir sus propias normas o por modificar radicalmente las existentes. Esta discrepancia entre lo que se escribe y lo que se hace, lejos de tratarse de un asunto sin importancia, constituye una irregularidad que influye de manera determinante en el problema de la violencia, ya que no existe algo así como un código reconocido, consultado y aceptado por todos los actores escolares.

La falta de consensos institucionales promueve la libre interpretación de las normas, iniciando un interminable ciclo de intervenciones tendenciosas y considerablemente subjetivas, las cuales, en lugar de mitigar los conflictos, desencadenan otros nuevos. Como afirma Osorio (2006): «existe la ley jurídica, pero no un sistema judicial que la aplique correctamente. Hay caudillos, dictadores y hasta monarcas disfrazados de presidentes. En fin, personajes que no pretenden ser representantes de la ley, sino ser ellos mismos la ley» (p. 120). Centrando la atención en el ámbito escolar secundario, Dussel (2005) ofrece una interesante lectura sobre las dificultades que se suscitan a la hora de intentar decir la ley en estos ámbitos:

Es común escuchar que la dificultad de enunciar o instaurar la ley se vincula con la masificación de la escuela media y el acceso de sectores de la población con otros códigos y disposiciones a las habituales en los alumnos de la escuela media. «Los hijos de los salvajes» de hoy son, muchas veces, objeto de prácticas expulsivas por parte de los adultos en la escuela que no saben o no pueden instaurar otros órdenes normativos. (p. 1113)

La interpretación y aplicación tendenciosa de las reglas (la irregularidad en el funcionamiento de los Acuerdos Institucionales de Convivencia constituye el ejemplo más claro) también representa, en cierto modo, una desconsideración a su función ordenadora? El manejo intencionado que los adultos hacen de las normativas supone el ejercicio de una peligrosa autonomía que, en ocasiones, converge en la toma de medidas autoritarias

\footnotetext{
7 En la mayoría de las instituciones seleccionadas es posible leer el contenido de los acuerdos de convivencia en afiches pegados en sus paredes. No obstante, su presencia pareciera no tener demasiado valor simbólico. Al respecto Southwell et al. (2015) sostienen: «resultaría importante para las escuelas revisar el sentido de ciertas normas y de su posterior exigencia, ya que estas contradicciones entre exigir por un lado pero hacer la vista gorda por otro parecen generar vínculos confusos respecto de la legalidad y de la norma» (p. 321 ).
} 
y excluyentes. Y esto es posible únicamente con la legitimación generalizada de la ilegalidad, es decir, con la aprobación de la mayoría. En un estudio enfocado en el análisis de los Acuerdos Institucionales de Convivencia, Dussel (2005) advierte que los usos tendenciosos de la ley escolar (por parte de los adultos) son una constante que puede evidenciarse en un número considerable de documentos. La construcción y el sostenimiento de una ley asimétrica, diferenciada y estratificada revela la transposición de ciertas costumbres políticas tendenciosas y cuestionables:

La ley es asunto de los débiles y no de los poderosos, porque quienes pueden, la sortean mediante conexiones o sobornos (...). La no inclusión de los adultos en la ley escolar, lejos de fundar una asimetría necesaria para la tarea pedagógica (que en todo caso sería deseable fundar en una legitimidad cultural y ética democrática), refuerza la idea de que solo los débiles son objeto de regulación normativa. (Dussel, 2005, p. 1114)

Así, lejos de tratarse de un asunto que concierne exclusivamente a los jóvenes, la autorregulación de los adultos es un hecho que - por otros mecanismos- promueve el desencadenamiento de hechos violentos; quizás no de forma directa, pero sí por medio de decisiones arbitrarias implementadas al margen o manipulando los reglamentos vigentes. Algunos relatos de los adultos entrevistados dan cuenta lo recién desarrollado:

La escuela tiene que ser apolítica y educar para la paz. Por eso nosotros estamos atentos a todos los brotes posibles de violencia. Nosotros tenemos que escanear el humor del grupo y estar muy encima; desgraciadamente a mí me sirvió lo que aprendí en el sistema carcelario.

Como nunca...; una vez tuvimos tres peleas seguidas en el aula a las trompadas en las que se dieron bastante (...); cuando me metí yo la ligué de costado. Lo peor que hay es meterse, pero hay preceptoras que están muy prácticas en las peleas. Me gustaría que hables con mi compañera. Ella tiene una cancha espectacular. Primero da trompadas y los empuja de atrás $\mathrm{y}$ de costado $-\mathrm{y}$ además esquiva- ¡vos tenés que ver! Por la experiencia que tiene es una peleadora ideal para contener situaciones de violencia que no pasan de las trompadas. Por suerte son solo problemas de liderazgo; son comunes, son frecuentes. En qué escuela no los hay. (Profesor en Construcción de la Ciudadanía, escuela del centro)

A veces empiezo siendo un poquito agresiva con los chicos y después los empezás a conocer... Ves que los querés y no los podés tratar mal. (Preceptora, escuela de la periferia norte)

$\mathrm{Al}$ anteponer el arbitrio y la imparcialidad, muchos educadores no solo ejercen una autoridad debatible en términos éticos, sino que también operan como reproductores y 
magnificadores del problema de la violencia. La desregulación generalizada se convierte entonces en un problema que trasciende las distancias generacionales. La ausencia de referencias claras y medidas de sencilla - y coherente- aplicación introduce la incertidumbre y la espontaneidad como prácticas habituales a la hora de determinar qué hacer frente a un hecho violento.

La problemática de la violencia es reconocida por el Estado en todos sus niveles (legislatura, ministerios, jefaturas distritales, facultades, escuelas, etcétera) y no faltan normativas pensadas por cada una de estas instancias para hacer frente a esta cuestión. Pese a esto, y teniendo en cuenta la información brindada por los informantes, pareciera que la forma en que tales normativas suelen ser implementadas queda supeditada al criterio y a la voluntad de la autoridad interviniente. A partir de esto podríamos decir, siendo un poco esquemáticos, que el Estado adopta un posicionamiento algo contradictorio. Por un lado, se preocupa en sancionar leyes y distribuir documentos destinados a mitigar la violencia (cuyo contenido, en términos generales, es adecuado y conveniente), pero, por otro, abandona tales documentos a su suerte, desentendiéndose de la aplicación y de la efectividad de los mismos.

Sobre el material documental referido a la violencia en las escuelas es pertinente atender a la opinión de dos integrantes de un equipo de orientación escolar (con funciones en la escuela de la periferia norte):

Yo particularmente creo que si cada docente leyera las comunicaciones que hay..., está todo, en comunicación está todo escrito (...). Te dicen hasta cómo abordar una situación en la que se te presenta un alumno con un arma en la escuela. Todo lo que tenés que hacer te lo dice. Y así para cada una de las situaciones; si hay presencia de sustancias tóxicas, etcétera. Está todo escrito en educación; es leer y apropiarte de eso, digamos.

Si bien hay una formación que te la da el instituto o la universidad, luego tenés que estar vos ahí y decir: «bueno yo estoy trabajando en educación, me encuentro con jóvenes y me encuentro con problemas que por ahí antes a un docente no le llegaba a los oídos» (de abuso, de maltrato familiar, de una serie de situaciones) (...). Tenés que tratar de buscar información, tratar de asesorarte, de preguntar a los inspectores. Hoy todos tenemos acceso al material.

Con una política discutible en materia de relevamiento y supervisión de las leyes, el Estado deposita el tratamiento de la violencia en las escuelas en un personal que se manifiesta superado, incapacitado y saturado de ocupaciones. El resultado es el ejercicio de una simulación a gran escala, en la cual el Estado se asegura también el haber tomado 
medidas en el asunto, incluso cuando es evidente que tales medidas, por sí solas, son insuficientes.

\section{Las intervenciones, estancadas entre la burocracia y la vorágine escolar}

Anteriormente hablamos de las dificultades que manifestaron algunos docentes al momento de realizar intervenciones tendientes a mitigar la violencia. Entre ellas, mencionamos el exceso de burocracia y la vorágine escolar como dos de los obstáculos más referenciados entre los informantes. A continuación nos detendremos en estas categorías, ya que no podemos pasar por alto el hecho de que, en ocasiones, la compleja red administrativa que caracteriza a los sistemas educativos modernos obstaculiza la resolución de diversas problemáticas acontecidas en las escuelas.

Es preciso aclarar que el automatismo y la impersonalidad que la burocracia introduce en los ámbitos escolares no suponen el desencadenamiento automático de acontecimientos violentos; la influencia es indirecta. La relación que podría condensarse en la frase «a mayor burocracia, mayor violencia» radica en que la burocracia - inhabilitando la reflexión y la acción de los actores escolares- dificulta y obstaculiza la resolución de los conflictos. En otros términos, podría decirse que el efecto de la burocracia sobre la violencia es magnificador, pero no por mecanismos coactivos, sino por la impotencia y la frustración que resultan del dominio de nadie (Arendt, 2006).

La burocracia, la rutina, el desapego, la falta de compromiso y una institucionalidad exigua en términos de contención material y simbólica promueven la continuidad de un automatismo que impide atender lo que acontece en los colegios en materia de vínculos, conflictos y convivencia. Siendo un poco esquemáticos, podría decirse que, una vez finalizado el horario escolar, todo es borrón y cuenta nueva: la vorágine se lo come todo y los problemas derivados de las relaciones personales solo pueden atenderse si ocurren antes del horario de salida. El sostenimiento de esta inamovible e infranqueable rutina supone el ejercicio de una peligrosa indiferencia por parte de los adultos. La omisión de los conflictos y la hipócrita reacción de asombro cuando estos se exteriorizan en el plano físico solo aseguran la perpetuidad y el agravamiento del fenómeno estudiado.

Si bien en el relato de los informantes adultos la cuestión de la burocracia y la vorágine escolar no son manifestadas exactamente con la misma denominación, consideramos que el relato de algunas experiencias y sensaciones vividas (por ejemplo, aquellas en las que se hace referencia a funciones mal desempeñadas, la pérdida de sentido de la ta- 
rea, o quejas que involucran en algún punto al sistema) pueden incluirse como testimonios de las categorías propuestas. A continuación citamos algunos ejemplos:

En el funcionamiento del sistema a veces uno se siente como que es un peoncito. Entonces cuando uno tiene que sacrificar una ficha en la partida de ajedrez ¿qué sacrifica primero? El peoncito. Entonces uno a veces siente eso, que es un poco descartable (...). Llega un punto donde uno termina siendo cómplice de toda esa burocracia tonta. Te ponés a pensar y uno se pelea con los pibes para que no rompan las cosas, cuando lo que tendríamos que hacer es perder tiempo y pelear contra el consejo escolar. Esas son las cosas las que te terminan distorsionando la cabecita. (Preceptor, escuela del barrio ferroviario)

Cuando a ellos les pasa algo y el profesor quiere continuar con la clase, en lugar de parar y decir «bueno a ver chicos qué les pasa», y por el contrario los saca y les dice «van para dirección», ellos lo ven como una situación de violencia. (Miembro del equipo de orientación escolar, escuela de la periferia norte)

La caracterización del aparato educativo como un sistema que no se halla en condiciones, la percepción del docente como una figura descartable comparable con el lugar que ocupa un "peoncito» en el tablero de ajedrez (es decir, una pieza sacrificable y de poca relevancia), la demanda de una mayor presencia de los organismos responsables de administrar recursos o la mecanización observable en las clases de algunos profesores representan factores - comúnmente relacionados con la idea de burocracia- tendientes a la indiferencia, al descuido de las responsabilidades laborales y, en ocasiones, a la exacerbación de un clima hostil que termina por naturalizarse.

En Sobre la violencia, Arendt (2006) entiende la burocracia «como un complejo sistema de oficinas en donde no cabe hacer responsables a los hombres, ni a pocos ni a muchos y que podría ser adecuadamente definida como el dominio de nadie» (p. 53). Si bien el análisis que propone la autora no se centra en cuestiones específicamente educativas, la hipótesis de que la burocracia comparte algunos elementos con la violencia nos invita a considerar su propuesta. Arendt atribuye a la burocracia un carácter tiránico, ya que al tratarse de un sistema que no está obligado a dar cuentas a nadie (es decir, que antepone la impersonalidad del documento a la persona), «no existe precisamente nadie al que pueda preguntarse por lo que se está haciendo» (Arendt, 2006).

En ocasiones, la burocracia ligada a los sistemas educativos modernos parecen funcionar como un obstáculo a la hora de combatir los problemas comúnmente asociados a la violencia. Lejos de tratarse de un asunto irrelevante, esta mediación impersonal hace que, tomando como referencia el relato del preceptor citado más arriba, algunos profe- 
sionales de la educación opten por eludir sus responsabilidades antes que verse envueltos en situaciones conflictivas. Siguiendo esta línea, sería comprensible - pero no justificable- el hecho de que un educador prefiera, por ejemplo frente a una pelea, esconderse en lugar de intentar desarticularla.

Cuanto más grande sea la burocratización de la vida pública, mayor será la atracción de la violencia. En una burocracia completamente desarrollada no hay nadie con quien discutir, a quien presentar agravios o sobre quien puedan ejercerse las presiones de poder. La burocracia es la forma de Gobierno en la que todo el mundo está privado de libertad política, del poder de actuar; porque el dominio de Nadie no es la ausencia de dominio, y donde todos carecen igualmente de poder tenemos una tiranía sin tirano. (Arendt, 2006, p. 110)

Si, asumiendo una postura algo ensayística, trasladamos las reflexiones de Arendt al ámbito educativo, podríamos decir que la burocracia, al establecer el dominio de nadie y la imposibilidad de acción, constituye uno de los elementos más agravantes en el asunto de la violencia. A través de la despersonalización, el automatismo y la irreflexión esta modalidad de administración genera las condiciones propicias para que muchos jóvenes — despreocupados de cuestiones operativas, legales y jurisdiccionales- habiten lo que podríamos denominar vacíos de autoridad, introduciendo allí sus propios códigos, considerablemente más simples aunque -impredecible y riesgosamente- más físicos.

Es preciso aclarar que el personal adulto no escapa a esta sustitución de normas: en muchas ocasiones, para no lidiar con los cuantiosos requisitos burocráticos varios docentes y autoridades manifestaron haber seguido sus propias reglas (para resolver un hecho comúnmente considerado violento). Si bien esto no representa un acto violento en términos físicos, creemos que este tipo de apropiaciones alimentan — aún más- el desconcierto que existe en torno a la problemática en cuestión, ya que, por lo general, las reglas propias suelen ser considerablemente subjetivas (agravando aún más los conflictos existentes o, inclusive, generando otros nuevos).

\section{Conclusiones}

Atendiendo a la información provista por los informantes, si bien la mayoría de los entrevistados adultos no dudó en afirmar que las escuelas en las que fueron entrevistados se hallaban atravesadas por un evidente o un grave problema de violencia, a la hora 
de solicitarles más detalles sobre la naturaleza de los hechos que ellos consideraban como violentos, advertimos que, salvo escasas excepciones, estos remitían a situaciones cuyas causas excedían la injerencia o las posibilidades de intervención del establecimiento al que hacían referencia. Esto quiere decir que el fenómeno, si bien existe (es decir, efectivamente hay un problema que puede leerse como un asunto asociado en algún punto con la violencia), se desprende de otro de mayor envergadura, que excede los límites físicos y simbólicos de lo escolar y se inscribe en el ámbito de lo social. Dicho de otro modo, el problema de la violencia en las escuelas no puede personificarse en el alumno, el docente o el padre protagonista del caso más resonante del diario matutino; se trata de un fenómeno de gran magnitud cuyas causas trascienden la acción individual de un agente catalogado - arbitraria y tendenciosamente - como violento.

A medida que avanzamos con la investigación, entendimos que no hay una respuesta única, ni un funcionario especializado, ni una manera ejemplar de combatir la violencia. De hecho, al afirmar esta es la mejor receta estaríamos recurriendo a modalidades de intervención generalistas, que remiten a esquemas ya caducos en nuestros tiempos. Además de ello, un discurso que pretendiera desterrar la violencia por completo se revelaría rápidamente ilusorio y carente de argumentos. Sin ir más lejos, en tiempos de revoluciones la violencia fue el medio predilecto para erigir las estructuras sociopolíticas que hoy conocemos; es por esto que no podemos pretender que una sociedad asentada sobre la base de la violencia se deshaga de esta con un documento, un discurso o una guía; en cierto modo esto representa un argumento contradictorio.

Sin embargo, también rechazamos por completo la creencia que la violencia es inherente a los seres humanos (como se afirma casi literalmente en muchos estudios referidos a la violencia escolar), como si la violencia fuera un mecanismo de ataque y defensa impreso desde el nacimiento. No solo habría que poner en cuestionamiento qué hay de inherente en el ser humano, sino que, además, esta afirmación colisiona con otra -igualmente recurrente- que supone que el problema de la violencia en las escuelas se deriva de un problema de violencia a escala social. Para ser claros en este punto, creemos que la violencia es una consecuencia de las relaciones desiguales de dominación, de la supresión de derechos, de los abusos, de las injusticias, de la amenazas, etcétera. No puede haber alumnos violentos porque no hay humanos violentos: la violencia no es una cualidad innata; esto es una construcción que, inclusive cuando es respaldada por teorías provenientes de diversos campos, es sumamente arbitraria y, sobre todo, peligrosa. 
Creemos que uno de los desafíos de la educación en estos tiempos es tratar de desalentar y sustituir el empleo de la fuerza apelando a un referente, a una causa, a un proyecto: algo que trascienda el plano individual y convenza a todos de que el encuentro con el otro y la construcción del consenso permiten multiplicar las fuerzas individuales y abren la posibilidad de alcanzar objetivos más grandes. Dicho de otro modo: no tiene sentido hacer uso de la violencia; pero no porque lo diga un docente, un directivo, un miembro de un equipo de orientación escolar o porque esté redactado en un documento, sino porque hay algo más grande, más fuerte y perdurable que se pierde cuando se emplea la fuerza: la pertenencia y protección de una cultura, la posibilidad de aceptar y de ser aceptado, la posibilidad de construir en vez de destruir. Si quienes trabajamos en las escuelas no creemos fervientemente en la potencia de la educación para cambiar y mejorar el presente, no podemos sorprendernos si los problemas asociados a la violencia (entre otros de igual relevancia) se agravan y multiplican con el paso del tiempo.

Asumiendo este desafío, cabría preguntarnos: ¿sobre qué referencias contemporáneas podemos asentarnos los adultos que trabajamos en las escuelas para construir una convivencia pacífica? Para responder esto es preciso, antes que nada, repasar brevemente una máxima de Meirieu (2007): «Cuando un adulto no tiene autoridad, es porque no encarna el porvenir» (p. 11). Esto quiere decir que como adultos y como miembros de una sociedad, pero fundamentalmente como educadores, tenemos la potencia y la responsabilidad de brindar herramientas a las nuevas generaciones para que estas ingresen progresivamente a un mundo que ellos mismos puedan habitar y mejorar. Siguiendo a Bleichmar: «Nuestro trabajo no es simplemente una rutina (...), no vamos simplemente a cumplir un horario, sino que creemos en la posibilidad de mejorar lo que hay o de producir algo nuevo» (2008, p. 57). En otras palabras, los profesionales de la educación deberíamos ser capaces de proveer aquellos medios necesarios para que los nuevos no colisionen con el mundo, sino que lo habiten de una manera cada vez más pacífica.

\section{Referencias}

Arendt, H. (2006). Sobre la violencia. Alianza.

Bleichmar, S. (2008). Violencia social-violencia escolar. Noveduc.

Brener, G., \& Kaplan, C. (2015). Violencias, escuela y medios de comunicación. En C. Kaplan (Dir.), Violencias en plural: sociología de las violencias en la escuela (77-102). Miño y Dávila. 
Cornejo, R., \& Redondo, J. (2001). El clima escolar percibido por los alumnos de enseñanza media: una investigación en algunos liceos de la Región Metropolitana. Última Década, 9(15), 11-52. http://dx.doi.org/10.4067/So718-22362001000200002

Chaves, M. (2010). Jóvenes, territorios y complicidades: una antropología de la juventud urbana. Espacio Editorial.

D’Angelo, L., \& Fernández, D. (2011). Clima, conflictos y violencia en la escuela. Unicef; Flacso.

Duschatzky, S., \& Corea, C. (2013). Chicos en banda: los caminos de la subjetividad en el declive de las instituciones. Paidós.

Dussel, I. (2005). ¿Se renueva el orden disciplinario escolar? Una lectura de los reglamentos de convivencia en la Argentina de la post-crisis. Revista Mexicana de Investigación Educativa, $10(27), 1109-1121$.

García-Villanueva, J., De la Rosa-Acosta, A., \& Castillo-Valdés, J. S. (2012). Violencia: análisis de su conceptualización en jóvenes estudiantes de bachillerato. Revista Latinoamericana de Ciencias Sociales, Niñez y Juventud, 10(1), 495-512.

Garriga-Zucal, J. (2016). El inadmisible encanto de la violencia. Cazador de Tormentas Libros.

Hegel, G. (1968). Filosofía del derecho. Claridad.

Kaplan, C. (2015). Violencias en plural: sociología de las violencias en la escuela. Miño y Dávila.

Kornblit, A. (Coord.) (2008). Violencia escolar y climas sociales. Biblos.

Litichever, L. (2012). ¿Qué se regula hoy en las escuelas?: una mirada sobre las prescripciones de los reglamentos de convivencia. Revista Iberoamericana de Educación, 1(59), 1-10. https:// doi.org/10.35362/rie5911403

Litichever, L., Machado, L., Núñez, P., Roldán, S., \& Stagno, L. (2008). Nuevas y viejas regulaciones: un análisis de los reglamentos de convivencia en la escuela media. Última Década, 16(28), 93-121. http://dx.doi.org/10.4067/So718-22362008000100006

Meirieu, P. (2007). Una pedagogía para prevenir la violencia en la enseñanza. Martínez Carranza.

Núñez, P. (2015). La producción escolar de la(s) juventud(es): desigualdad, convivencia y situaciones de discriminación en la escuela secundaria. Revista Cátedra Paralela, 12, 59-84.

Osorio, F. (2006). Violencia en las escuelas: un análisis desde la subjetividad. Noveduc. 
Páez-Martínez, R. (2009). Cuerpo reconocido: formación para la interacción sin violencia en la escuela primaria. Revista Latinoamericana de Ciencias Sociales, Niñez y Juventud, $7(2), 989-1007$.

Pineau, P. (2008). Como a noite engendra o dia e o dia engendra a noite. Revisando o vínculo da produção mútua entre escola e Modernidade. Pro-posiçoes, 19(3), 83-104. http://dx.doi.org/10.1590/S0103-73072008000300005

Southwell, M. (2018). Notas sobre la intermitente democratización de la secundaria. En P. Núñez (Comp.), Convivencia y escuela secundaria. Organización de Estados Iberoamericanos.

Southwell, M., Fridman, D., Litichever, L., Núñez, P., \& Fajardo, J. P. (2015). Vínculos inter e intra generacionales en la escuela media: cambios y continuidades en el formato escolar, la convivencia y la construcción de la ciudadanía. En A. Pereyra (Comp.), Prácticas pedagógicas y políticas educativas: investigaciones en el territorio (311-340). Editorial Universitaria Unipe. 